\title{
Ice hockey injuries: incidence, nature and causes
}

\author{
Y. Tegner MD, $\mathrm{PhD}^{1}$ and $\mathrm{R}$. Lorentzon $\mathrm{MD}, \mathrm{PhD}^{2}$ \\ ${ }^{1}$ Department of Orthopaedics, The Ermeline Clinic, Luleå, Sweden \\ 2 Department of Orthopaedics, University Hospital of Umeä, Sweden
}

In this prospective study, we have investigated incidence of injuries of different severity, types of injury, and mechanisms of injury during ice hockey games. All twelve Swedish elite hockey teams were observed during the season 1988-1989 when a total number of 664 games were played. There was a total number of 285 injuries, of which the majority were minor $(61 \%)$ and only $9 \%$ were classified as major. Seventy-four per cent of the injuries occurred during games and $26 \%$ during practice. The overall incidence of injury was 53.0 per 1000 player-game hours. Eighty-five per cent of injuries were caused by trauma and $15 \%$ by over-use. Injuries were most often localized to the head/face $(39 \%)$ or the lower limb $(32 \%)$. Most injuries resulted from stick contact or player contact including checking. A reduction of minor and moderate injuries should be possible by stricter enforcement of the hockey rules, and more widespread use of visors.

Keywords: Ice hockey, sports injuries, visors

Ice hockey is associated with many potential dangers because of contact between players or with stick, puck, skate blades, boards or goal posts $2,3,5,8,10,12,13$. We reported a high incidence of injury during hockey games, while that during practice was very $10 w^{5}$. Although the majority of injuries were minor $(73 \%)$ and only $8 \%$ major ${ }^{5}$, extremely severe injuries especially to the eye and the spine have previously been noted to occur in hockey $1,7,14,15$.

The purpose of this investigation was to extend our experience from one Swedish elite ice hockey team ${ }^{5}$, and prospectively to gather information on injuries from all 12 teams of the highest hockey division (elite league). The present report covers the 1988-1989 season.

\section{Material and methods}

Before the start of the hockey season 1981-1989, the physicians of all teams of the highest Swedish hockey division (elite league) attended an information meeting concerning the background and purpose of this investigation. The physicans were instructed to

Address for correspondence: Dr Yelverton Tegner, Department of Orthopaedics, The Ermeline Clinic, PO Box 195, S-951 23 Luleå, Sweden

(C) 1991 Butterworth-Heinemann Ltd. 0306-3674/91/020087-03 record all injuries on a special card ${ }^{5}$ and to send these cards to one of the authors (YT). Thus, clinical examination and registration were always performed by the team physicans. Attendence records for practice sessions and games were, in most teams, kept by the assistant coach.

Most Swedish elite players are subsidized amateurs having a half-time appointment in addition to ice hockey.

Injury was defined as any injury occurring during ice practices or games and causing the player to stop playing or to miss the next practice session or game $^{5,16}$. Facial lacerations, which are common in ice hockey, but do not cause absence from practice or games, are also reported.

Injuries were classified as traumatic or over-use injuries. In the latter category there was an often insidious and gradually increasing intensity of discomfort, but no obvious trauma. Injuries were also classified into three categories of severity: minor (an absence from practice of less than 7 days), moderate (an absence of 8 to 30 days), and major (an absence of over 30 days). Return to participation in practice or game after an injury was determined by the team physicians.

There were 12 teams in the highest Swedish hockey division. These teams played a total of 664 games. For purposes of calculating the incidence of injury during games, six players were assumed to be on the ice at any one time, making a total of 3984 player-game hours.

\section{Results}

There was a total of 285 injuries. These 285 injuries occurred at 267 occasions; at 18 times one player had two injuries at one and the same time. As for severity, $174(61.1 \%)$ injuries were classified as minor, $66(22.3 \%)$ were moderate, and $25(8.8 \%)$ were major. In 20 cases, the severity of the injury has not been possible to establish. One player was permanently severely disabled and became tetraplegic due to a fracture-dislocation of the cervical spine. Two players had to terminate their career with chronic knee instability and disabling multidirectional shoulder instability respectively.

Of the total 285 injuries, 211 (74.0\%) occurred during games and $74(26.0 \%)$ during practice. For the individual player, the incidence of injury was 53.0 per 
1000 player-game hours. Injuries during games were fairly evenly distributed over the different game periods, $31 \%$ of all injuries occurring in the first period, $38 \%$ in the second period, and $28 \%$ in the third period.

Of all injuries, $228(85.4 \%)$ were caused by trauma and $39(14.6 \%)$ by over-use. The types of traumatic injuries are shown in Table 1 and the localization of all injuries is shown in Table 2. The injuries were localized to the upper limbs in $17.6 \%$ of the cases, and to the lower limb in $31.6 \%$. The corresponding figures for head and back were $39.2 \%$ and $11.4 \%$, respectively.

The mechanisms of injury are shown in Table 3. Injuries were most often caused by stick contact or player contact, including tackling (checking). Foul

Table 1. Types of hockey injuries

\begin{tabular}{lrr}
\hline Type of injury & No. & $\%$ \\
\hline Strain/sprain & 69 & 24.2 \\
Laceration & 68 & 23.9 \\
Contusion & 52 & 18.2 \\
Fracture & 26 & 9.1 \\
Tooth lesion & 15 & 5.3 \\
Superficial wound & 10 & 3.5 \\
Dislocation & 9 & 3.2 \\
Concussion & 8 & 2.8 \\
Miscellaneous & 28 & 9.8 \\
\hline
\end{tabular}

Table 2. Localization of hockey injuries

\begin{tabular}{lrr}
\hline Location & No. & $\%$ \\
\hline Head/face & 107 & 39.4 \\
Knee & 36 & 13.2 \\
Hip/thigh & 33 & 12.1 \\
Back/trunk & 31 & 11.4 \\
Shoulder & 25 & 9.2 \\
Lower leg/foot & 17 & 6.3 \\
Hand/finger & 12 & 4.4 \\
Arm & 11 & 4.0 \\
\hline
\end{tabular}

Table 3. Mechanisms of injury

\begin{tabular}{lrr}
\hline Mechanism & No. & $\%$ \\
\hline Stick contact & 68 & 25.5 \\
Player contact (including checking) & 64 & 24.0 \\
Puck contact & 30 & 11.2 \\
Collision with boards or goal posts & 26 & 9.7 \\
Fall - no contact & 11 & 4.1 \\
Skate contact & 4 & 1.5 \\
Miscellaneous & 25 & 9.4 \\
Over-use & 39 & 14.6 \\
\hline
\end{tabular}

play according to the referee's decision, caused only $8 \%$ of the injuries.

\section{Discussion}

A high incidence of injury in ice hockey games has previously been reported by $\mathrm{us}^{5,6}$, as well as by others 4,13 . In this study, the total incidence of injury during games was 53.0 per 1000 hours for the individual player. This figure is $\mathbf{1 . 5}$ times lower than the corresponding figure of 78.8 recently reported for one Swedish elite hockey team which was closely observed during three consecutive seasons ${ }^{5}$. The lower incidence in this study might be explained by incomplete registration of injuries, especially minor injuries such as facial wounds, by the team physicians in the 12 participating elite teams. Bias might also have been introduced by observing the teams for only one season. Players from certain teams might also be more liable to injury because of previous training, injuries or misuse of hockey protective equipment. In this context, it might be noted that there seems to be no correlation between leg muscle strength and injury rate in hockey players ${ }^{9}$.

A considerable number of injuries were localized to the face, predominantly lacerations caused by the opponent's stick. Many of these lacerations can be prevented by wearing a visor ${ }^{5}$. The same mechanisms can cause both harmless facial wounds or severe eye injuries resulting in blindness ${ }^{1,7}$. Mandatory use of visors is presently being introduced into Swedish senior hockey.

Contusions were common, usually from stick, body or puck contact. Stricter enforcement of the rules prohibiting stick violations is probably the best preventive measure, although better protective devices might also play a role. The fact that only $8 \%$ of the injuries was associated with a penalty suggests that referees may presently allow dangerous play.

\section{References}

1 Antaki S, Labell P, Dumas J. Retinal detachment following hockey injury. Can Med Assoc I 1977; 117: 245-6.

2 Bouchard F, Blessur au Hockey majeur; 3 ans d'ètude. Can Med Assoc J 1977; 117: 640-3.

3 Gerberich SG, Finke R, Madden M, Priest, JD, Aamoth G, Murray K. An epidemiological study of high school ice hockey injuries. Childs Nero Syst 1987; 3: 59-64.

4 Jörgensen U, Schmidt-Olsen S. The epidemiology of ice hockey injuries. Br J Sports Med 1986; 20: 7-9.

5 Lorentzon R, Wedrén H, Pietilä T. Incidence, nature, and causes of ice hockey injuries. A three-year prospective study of a Swedish elite ice hockey team. Am J Sports Med 1988; 16: 392-6.

6 Lorentzon $\mathrm{R}$, Wedrén $\mathrm{H}$, Pitetilä T. Injuries in international ice hockey. A prospective, comparative study of injury incidence and injury types in international and Swedish elite ice hockey. Am J Sports Med 1988; 16: 389-91.

7 Pashby TJ. Eye injuries in Canadian amateur hockey. Am J Sports Med 1979; 7: 254-7.

8 Pförringer W, Smasal V. Aspects of traumatology in ice hockey. J Sports Sciences 1987; 5: 327-36.

9 Posch E, Haglund J, Eriksson E. Prospective study of concentric and eccentric leg muscle torques, flexibility, physical conditioning, and variation of injury rates during one season of amateur ice hockey. Int J Sports Med 1989; 10: 113-17. 
10 Rielly MF. The nature and causes of hockey injuries. A five-year study. Athletic Training 1982; 17: 88-90.

$11 \mathrm{Sim} \mathrm{FH}, \mathrm{Chao}$ EJ. Injury potential in modern ice hockey. Am J Sports Med 1978; 6: 378-84.

12 Sim FH, Simonet WT, Melton LJ, Lehn TA. Ice hockey injuries. Am I Sports Med 1987; 15: 30-40.

13 Sutherland GW. Fire on ice. Am J Sports Med 1976; 4: 264-9.
14 Tator $\mathrm{CH}$, Edmonds VE. National Survey of spinal injuries in hockey players. Can Med Assoc J 1984; 130: 875-80.

15 Tator, CA, Ekong CEU, Rowed DW et al. Spinal injuries due to hockey. Can I Neurol Sci 1984; 11: 34-41.

16 Vinger PF, Hoerner EF (eds) 'Sports Injuries; The unthwarted epidemic. Boston: John Wright \& PSG Inc, 1982.

\section{News}

\section{Sink or Swim?}

It is reported that the Minister of Education's Advisory Committee on Physical Education and Sport is to recommend that all children be taught to swim at least $25 \mathrm{~m}$ by the age of 11 . This would encourage an effective sport for mass fitness and be a major step forward in preventive medicine as drowning has always caused more deaths in the UK than all other sports injuries put together. In the last 3 years almost 200 British children under 15 have drowned; 80 per cent were unable to swim (The Guardian, 20 February 1991). Any doctor who has struggled in vain to resuscitate a drowned child will have wondered why this obvious recommendation has not long been public policy.

It is with dismay that we read of the Minister's negative response to this recommendation and hope that reconsideration will lead to the saving of young lives.

\section{L-Tryptophan and Eosinophilia Myalgia Syndrome (EMS)}

The Department of Health has banned the sale of all foods containing added tryptophan (except under strictly defined medical prescription). This follows the discovery that EMS may occur in response to very small amounts of tryptophan (and/or one of its unidentified contaminants), often in 'health' supplements in which its presence may be hidden in such words as 'amino-acid mix'.

The EMS may include myalgia, arthralgia, fever, oedema and rash, with eosinophilia usually over $2000 / \mathrm{mm}^{3}$.

Source: Department of Health Circular PL/CMO(90)6

\section{Asian Federation of Sports Medicine}

We warmly congratulate our colleagues on their foundation of the Asian Federation of Sports Medicine under the aegis of FIMS. We are delighted that the founding officers are all members of BJSM's Editorial Board, Professor Qu Mian-Yu (President), Dr Nishat Mallick (Vice President) and Dr Kai Ming Chan (Secretary). 